\title{
Inclusion of coexisting morbidity in a TBSA\% and age based model for the prediction of mortality after burns does not increase its predictive power
}

Laura Pompermaier, Ingrid Steinvall, Mats Fredrikson and Folke Sjöberg

Linköping University Post Print

Tweet

N.B.: When citing this work, cite the original article.

Original Publication:

Laura Pompermaier, Ingrid Steinvall, Mats Fredrikson and Folke Sjöberg, Inclusion of coexisting morbidity in a TBSA\% and age based model for the prediction of mortality after burns does not increase its predictive power, 2015, Burns, (41), 8, 1868-1876.

http://dx.doi.org/10.1016/j.burns.2015.09.017

Copyright: Elsevier

http://www.elsevier.com/

Postprint available at: Linköping University Electronic Press

http://urn.kb.se/resolve?urn=urn:nbn:se:liu:diva-124131

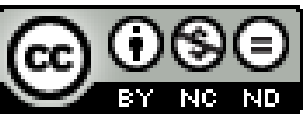




\title{
Inclusion of coexisting morbidity in a TBSA\% and age based model for the prediction of mortality after burns does not increase its predictive power
}

Laura Pompermaier, $\mathrm{MD}^{\mathrm{a}}$, Ingrid Steinvall, $\mathrm{PhD}^{\mathrm{a}}$, Mats Fredrikson, $\mathrm{PhD}^{\mathrm{b}}$ Folke Sjöberg, $\mathrm{MD}$, $\mathrm{PhD}^{\mathrm{a}, \mathrm{b}, \mathrm{c}}$

${ }^{\text {a }}$ The Burn Centre, Department of Hand and Plastic Surgery, Linköping University, Region of Östergötland, Linköping, Sweden.

${ }^{\mathrm{b}}$ Department of Clinical and Experimental Medicine, Faculty of Health Sciences, Linköping University, Linköping, Sweden.

${ }^{\text {c } D e p a r t m e n t ~ o f ~ A n a e s t h e s i o l o g y ~ a n d ~ I n t e n s i v e ~ C a r e, ~ R e g i o n ~ o f ~ O ̈ s t e r g o ̈ t l a n d, ~ L i n k o ̈ p i n g, ~}$ Sweden.

Corresponding author: Laura Pompermaier. The Burn Centre, Linköping University Hospital, Linköping, 58185, Sweden. Telephone: +46 (0)101033732. E-mail:

laura.pompermaier@regionostergotland.se.

\begin{abstract}
Introduction: Several models for predicting mortality have been developed for patients with burns, and the most commonly-used are based on age and total body surface area (TBSA \%). They often show good predictive precision as depicted by high values for area under the receiver operating characteristic curves (AUC). However the effect of coexisting morbidity on such prediction models has not to our knowledge been thoroughly examined. We hypothesised that adding it to a previously published model (based on age, TBSA\%, full
\end{abstract}


thickness burns, sex, and need for mechanical ventilation) would further improve its predictive power.

Methods: We studied 772 patients admitted during the period 1997-2008 to the Linköping University Hospital National Burn Centre with any type of burns. We defined coexisting morbidity as any of the medical conditions listed in the Charlson list, as well as psychiatric disorders or drug or alcohol misuse. We added coexisting medical conditions to the model for predicting mortality (age, TBSA\%, and need for mechanical ventilation) to find out if it improved the model as assessed by changes in deviances between the models.

Results: Mean (SD) age and TBSA \% was 35 (26) years and 13 (17) \%, respectively. Among 725 patients who survived, 105 (14\%) had one or more coexisting condition, compared with 28 (60\%) among those 47 who died. The presence of coexisting conditions increased with age $(\mathrm{p}<0.001)$ among patients with burns. The AUC of the mortality prediction model in this study, based on the variables age, TBSA\%, and need for mechanical ventilation was 0.980 ( $n=772$ ); after inclusion of coexisting morbidity in the model, the AUC improved only marginally, to 0.986 . The model was not significantly better either.

Conclusion: Adding coexisting morbidity to a model for prediction of mortality after a burn based on age, TBSA\%, and the need for mechanical ventilation did not significantly improve its predictive value. This is probably because coexisting morbidity is automatically adjusted for by age in the original model.

\section{Introduction}

During recent decades, mortality after burns has decreased considerably [1-5].There are many reasons for this which are related both to advances in intensive care [2, 6], and to the introduction of modern surgical techniques $[7,8]$. However, mortality remains an important indicator of quality of life after burn care, and many models have been developed to predict 
the risk [5, 9-14] and to provide a baseline. The timely identification of risk factors in such models might help clinicians to reduce the mortality after burns further.

In 1961 Baux published a simple and effective formula to predict mortality after burns: "percentage mortality = age + percentage of total body surface area burned (TBSA \%)”. Since then several models have been developed and many different variables have been introduced. Mortality increases with age and the size of the burn, and inhalation injury often worsens the prognosis $[5,9,10,15,16]$. The role of sex, however, is conflicting [5, 17-23]. Clinical observations have suggested that the patient's coexisting diseases may play an important part in the likelihood of survival after a burn, but their impact on the risk of death is controversial [15, 19, 20, 24-26] and deserves further examination. However, we think that a limitation in many models is the lack of proper data about coexisting diseases, and we hypothesised that adding the information to a model with otherwise good predictive ability [10] could further improve the model.

The aim of the present study was therefore to investigate the effect of adding the factor coexisting morbidity to a model that predicts mortality, which includes age, TBSA\%, and the need for artificial ventilation (Galeiras model) [10] in a larger sample of burned patients from one national burn unit in Sweden. We have a unique opportunity to assess coexisting morbidity, as all contacts with health care are recorded in the Swedish National Patient Registry (NPR) [27].

\section{Methods}

\section{Sources of data}

Since 1993 all patients with burns admitted to the Linköping University Hospital Burn Centre have been prospectively recorded in the local Burn Unit Database. Among the variables are age, sex, date of admission, type of burn (scald, contact with a hot object, friction, open 
flame including explosion caused by fire, electricity, chemical injury, or radiation), size of burn (TBSA \% and full thickness burns, FTB \%), duration of stay, need of mechanical ventilation during the first 72 hours after admission, and death by any cause during admission $[28]$.

Since 1987 all Swedish inpatient events in public hospitals have been recorded centrally in the Swedish National Inpatient Register [27]. In case of death the cause is recorded in the Cause of Death Register. The variables recorded in the Inpatient Register that have been used in this study were: coexisting morbidity, duration of survival after the burn and, in case of death, the cause.

The data are tracked by the unique Swedish date of birth combined with a social security number to a specific Personal Identity Number [29].

\section{Details of patients}

All the patients admitted between 1 January 1997 and 31 December 2008 for new burns (thermal, electrical, or chemical) were included, while admissions for skin diseases were excluded. All the patients were recorded in the Burn Unit Database.

To obtain as accurate a picture of coexisting morbidity as possible we requested information from the National Patient Registry about the group being studied between 1 January 1987 and 31 December 2008, for at least 10 years before the actual burn.

A total of 831 patients were admitted to the Burn Unit during the observation period, 59 of whom were not registered on the National Registry because they were foreigners. A total of 772 patients were therefore included in the analysis.

\section{Coexisting diseases}


Coexisting diseases were defined as those medical conditions recorded for each patient up to and including admission to the Burn Unit. All diagnoses are reported in the Registry according to the International Classification of Diseases-9 (ICD-9) from 1987 to 1996 and ICD-10 from 1997 onwards. A new method was developed in 1987 to evaluate the impact of coexisting morbid conditions on the risk of mortality prospectively [30]. A weighted index or Charlson Index (from 1 to 6) was attributed to every disease seen, and conditions with a higher index implied a higher risk of mortality. Since then we have used the Charlson Index as a prognostic indicator. The conditions described in the original article [30] have been successively classified in 17 diagnostic categories and the diagnoses, initially reported in ICD-9 codes, have also been validated for ICD-10 [31] (Table A.1).

Psychiatric disorders, even drug and alcohol misuse, are not included in the Charlson Index. The overrepresentation of mental disorders or alcoholism in burned patients is well known, [32-34] and so the effect on mortality was also evaluated. We therefore added 4 groups to the 17 Charlson conditions: mild mental illness, serious mental illness, drug misuse, and alcohol misuse (Table A.2). In our definition, serious mental illness includes major depression, schizophrenia, bipolar disorder, serious obsessive compulsive disorder, panic disorder, post-traumatic stress disorder, and borderline personality disorder, as suggested from the American National Alliance on Mental Illness.

\section{Statistical analysis}

Data are presented as mean (SD) or median $\left(10^{\text {th }}-90^{\text {th }}\right.$ centile) and $95 \%$ CI. We used the Mann-Whitney U test to test for statistically significant differences between groups concerning continuous variables, and for nominal dichotomous variables we used Fisher's exact test. These analyses were made with the help of Statistica (v.10, StatSoft Inc. USA). We made multivariable logistic regression analyses using STATA (STATA v.12.0, Stata Corporation. LP, TX, USA). Probabilities of less than 0.05 were accepted as significant. The 
calibration was assessed using the Hosmer-Lemeshow goodness-of-fit statistic. All statistical tests were two-tailed.

We calculated the AUC for the following models: Galeiras’s [10], the combination of Galeiras’s and Charlson’s Index, and finally the combination of Galeiras’s model, Charlson’s Index, and psychiatric disorders (mild and severe).

The models was also compared by calculating the deviance between the log likelihood (LL) for Galeiras's model and the LL for the combination of Galeiras’s model and Charlson’s Index, and finally the LL for the combination of Galeiras’s model, Charlson's Index, and psychiatric disorders by using the Chi square distribution.

\section{Results}

Characteristics of patients and their coexisting conditions are shown in Tables 1 and 2. The incidence of various medical conditions for patients who survived and those who died is shown in Table 3. Table 4 presents effect on mortality of Charlson's conditions or psychiatric disorders or substance misuse. Table 5 reports characteristics of patients according to the variables categorised in the Galeiras model, in relationship to the survival status. Finally, Table 6 shows Galeiras model combined with Charlson Index and psychiatric disorders.

\section{Effect of coexisting conditions on the prediction of mortality}

We find that severe psychiatric disorders, alcohol misuse and drug misuse were significantly associated with mortality, whereas mild psychiatric disorders were not (Table 3). The Charlson Index in combination with psychiatric disorders, alcohol and drug misuse was associated with mortality, but of the psychiatric disorders, only severe psychiatric conditions were significant (Table 4). Pre-existing Charlson's conditions alone were significantly associated with mortality (95\%CI, 1.60-2.43, $\mathrm{p}<0.001)$, whereas it lost significance in 
combination with Galeiras model and severe psychiatric disorders (Table 6). Both Galeiras original model with our data and the combination of Galeiras's and Charlson's Index have an AUC of 0.980, the combination of Galeiras model with Charlson's Index and psychiatric disorders has an AUC of 0.986. A comparison between the models showed that adding Charlson index to the Galeiras model did not improve the model significantly, $\mathrm{p}=0.15$. Adding both Charlson and psychiatric disorders did not either make a model that was significantly better than just using Galeiras, $\mathrm{p}=0.06$.

\section{Discussion}

The strength of this study is the amount and quality of information about patients with burns admitted to one of the burn centres in Scandinavia over a period of 12 consecutive years; data are obtained from fitting together two detailed registries: the Burns Unit Database and the Swedish National Patients Registry. The description of our patients is therefore accurate and the risk of omitting information about coexisting diseases has been reduced because we report medical conditions that were recorded for at least 10 years before the burn.

A limitation of retrospective studies of data from registries lies in the accuracy of the original reporting; this is a variable related to the individual accuracy of whoever records the data, and is therefore difficult to account for. Since 1947 every person permanently resident in Sweden has had a personal identity number (PIN) [29]; since 2000 those who intend stay in Sweden for less than one year receive not a PIN but a coordination number. The data collected in the Swedish Patients Register is based only on the PIN, so those with a coordination number (such as tourists or refugees without a residence permit) will not be included. However, the percentage of missing values for all variables reported during the study period is 7\%. A total of 831 patients were registered in the Burns Unit Database, 59 of who were missing from the National Patients Registry. The Burns Unit 
Database, and consequently our analysis, does not concern people who were burned but died before admission to hospital.

The 772 patients admitted to Linköping University Hospital with burns between 1997 and 2008 were mainly young and healthy with moderately severe burns, and most were men. Mortality was low (6\%) and limited to those over 40 years old (except one under 30 who died of extensive and severe burns). The low mortality rate should be acknowledged as a potential study limitation, since it limits the statistical power. Thus, a multicenter study with larger number of patients would be justified to ascertain the validity of our results. However, our finding that age, size and depth of burn and need for mechanical ventilation had adverse effects on the patient's chance of survival is in accordance with previously published results [10] and this consistency suggests that our results are not due to chance alone.

Children less than 10 years old were the largest age group (23\%), and they have few coexisting conditions (7\%) or just one condition, and none died. However, we think that the size of the burn, together with its management and that of any complications, are more important for the outcome in children than any pre-existing medical condition. This was confirmed by Kraft et al [35] who showed that regardless of coexisting morbidity, mortality in children increases significantly with the size of the burn, and a TBSA of $62 \%$ is a crucial threshold. Fortunately the severity of burns in our youngest sample was restricted, mean (SD) TBSA was 7.7 (8.9) \% and full thickness burn 1.2 (6.0) \%, and this explains the outcome.

Because it seems to be accepted that coexisting morbidity increases with age in the general population, we investigated whether it holds true for patients with burns. We found that people with pre-existing conditions tend to be appreciably older (mean age 57 years, SD 25) than healthy people (mean age 30, SD 24), and patients who survive burns are usually healthier than those who do not, with presence of coexisting conditions in 14 
respectively $60 \%$ of patients. Cerebrovascular diseases are the most common among those listed by Charlson; most of those patients who survive are otherwise healthy, whereas many of those who do not survive have heart disease or diabetes, and nearly $15 \%$ of them have some form of malignancy (Table A.3). It is still true that Charlson's coexisting conditions are related to mortality, but to a lesser extent than age, size of burn, and need for mechanical ventilation.

Thombs et al [24] showed in a large American study that metastatic cancer increased in-hospital mortality after burns, but we do not know if the cancer or the burn was the ultimate cause of death. However, the comparison is interesting and the results unexpected: heart and renal diseases have similar adverse effects on survival after burns, both in Sweden and across the Atlantic; diabetes, dementia, and ulcers are associated with worse outcomes in Sweden but they do not have the same impact on mortality in the US, where, instead HIV/AIDS and obesity are an unfavourable impact on prognosis but are not present (or not reported) in our registries [24]. The differences in the range of diseases can depend on social and cultural factors, but probably it is the difference in the size of the samples that influences the results most (Table A.3).

Our data confirm observations made in previous studies [24, 33, 34], and our clinical experience: the real curse for people with burns is a psychiatric condition or substance misuse. Charlson did not include the effect of psychiatric disorders or drug or alcohol consumption in her analysis, probably because these conditions were not common in the group that she studied (women with primary breast carcinoma) [30]. Because of the lack of a published validated system for the classification and scoring of mental diseases, we decided to analyse those diagnoses found in the Diagnostic and Statistical Manual of Mental Disorders, 4th ed. that we arbitrarily considered to be relevant to our patients. However, although mental disorders are important in patients with burns, we found that these have a small effect on 
prognosis. In particular, the presence of severe psychiatric disorders leads to serious consequences for people with burns; alcohol misuse is over-represented among those who died, but contrary to the findings of other authors [16, 24], its effect in our patients was not significantly fatal. Instead, mild psychiatric disturbances seemed to have a protective effect, both alone and in combination with severe psychiatric conditions, but this outcome lacks statistical significance_and deserves further investigations.

We can certainly confirm the validity of Galeiras's [10] equation: given the finding that our prediction is so close to that of Galeiras, it supports the robustness of their prediction, both using the original and the fitted Galeiras model. Surprisingly (and in contradiction of our hypothesis) we found that coexisting morbidity does not improve the predictive value of mortality in Galerias's series: we used the equation with the addition of variables from the Charlson Index, or psychiatric disorders, or both together, but failed to show a substantial improvement. More precisely, inclusion of pre-existing medical conditions increased the predictive power of the model minimally, but not significantly. We confirmed what had already been verified by older samples [15]: that age alone, independent of coexisting conditions, increases the risk of mortality in hospital. However, age is one of the factors used in Galeiras's equation and, as is evident from our tables, coexisting morbidities are already adjusted for in the original model by age.

A new and interesting perspective in calculation of mortality risk in elderly with burns is the consideration of biological rather than chronological age. Masud et al. [36] assigned a frailty score (between 1 and 7) [37] to each patient over 65 years old and with TBSA greater than $10 \%$ admitted to an intensive care unit during a 4 years period. Interestingly, survivors had significantly lower frailty score than non survivors. Unfortunately, we cannot verify the effect of frailty on our burn population, because our data 
are collected retrospectively and our database does not contain the information necessary to score frailty.

\section{Conclusions}

Age, TBSA\%, and percentage of full-thickness burns undoubtedly have an impact on the risk of mortality among burned patients. We have confirmed the strong predictive value of Galeiras’s model for the prediction of mortality in our series of patients. However, adding coexisting morbidity to Galeiras’s model did not improve the prediction of mortality among our burned patients and using Galeiras original model with our data predicted mortality almost as good as fitting a new model to our data.

\section{References}

[1] Brusselaers N, Hoste EA, Monstrey S, Colpaert KE, De Waele JJ, Vandewoude KH, et al. Outcome and changes over time in survival following severe burns from 1985 to 2004. Intensive care medicine. 2005;31:1648-53.

[2] Engrav LH, Heimbach DM, Rivara FP, Kerr KF, Osler T, Pham TN, et al. Harborview burns-1974 to 2009. PloS one. 2012;7:e40086.

[3] Roberts G, Lloyd M, Parker M, Martin R, Philp B, Shelley O, et al. The Baux score is dead. Long live the Baux score: a 27-year retrospective cohort study of mortality at a regional burns service. The journal of trauma and acute care surgery. 2012;72:251-6.

[4] Jackson PC, Hardwicke J, Bamford A, Nightingale P, Wilson Y, Papini R, et al. Revised estimates of mortality from the Birmingham Burn Centre, 2001-2010: a continuing analysis over 65 years. Ann Surg. 2014;259:979-84.

[5] Ryan CM, Schoenfeld DA, Thorpe WP, Sheridan RL, Cassem EH, Tompkins RG. Objective estimates of the probability of death from burn injuries. N Engl J Med. 1998;338:362-6.

[6] Pereira C, Murphy K, Herndon D. Outcome measures in burn care. Is mortality dead? Burns : journal of the International Society for Burn Injuries. 2004;30:761-71. 
[7] Ong YS, Samuel M, Song C. Meta-analysis of early excision of burns. Burns : journal of the International Society for Burn Injuries. 2006;32:145-50.

[8] Vehmeyer-Heeman M, Van Holder C, Nieman F, Van den Kerckhove E, Boeckx W. Predictors of mortality: a comparison between two burn wound treatment policies. Burns : journal of the International Society for Burn Injuries. 2007;33:167-72.

[9] Osler T, Glance LG, Hosmer DW. Simplified Estimates of the Probability of Death After Burn Injuries: Extending and Updating the Baux Score. The Journal of trauma. 2009.

[10] Galeiras R, Lorente JA, Pertega S, Vallejo A, Tomicic V, de la Cal MA, et al. A model for predicting mortality among critically ill burn victims. Burns : journal of the International Society for Burn Injuries. 2009;35:201-9.

[11] Sheppard NN, Hemington-Gorse S, Shelley OP, Philp B, Dziewulski P. Prognostic scoring systems in burns: a review. Burns : journal of the International Society for Burn Injuries. 2011;37:1288-95.

[12] Hussain A, Choukairi F, Dunn K. Predicting survival in thermal injury: A systematic review of methodology of composite prediction models. Burns : journal of the International Society for Burn Injuries. 2013.

[13] Belgian Outcome in Burn Injury Study G. Development and validation of a model for prediction of mortality in patients with acute burn injury. Br J Surg. 2009;96:111-7.

[14] Tobiasen J, Hiebert JH, Edlich RF. Prediction of burn mortality. Surg Gynecol Obstet. 1982;154:711-4.

[15] Lundgren RS, Kramer CB, Rivara FP, Wang J, Heimbach DM, Gibran NS, et al. Influence of comorbidities and age on outcome following burn injury in older adults. Journal of burn care \& research : official publication of the American Burn Association. 2009;30:307-14.

[16] Raff T, Germann G, Barthold U. Factors influencing the early prediction of outcome from burns. Acta chirurgiae plasticae. 1996;38:122-7.

[17] Steinvall I, Fredrikson M, Bak Z, Sjoberg F. Mortality after thermal injury: no sex-related difference. J Trauma. 2011;70:959-64. 
[18] George RL, McGwin G, Jr., Schwacha MG, Metzger J, Cross JM, Chaudry IH, et al. The association between sex and mortality among burn patients as modified by age. J Burn Care Rehabil. 2005;26:416-21.

[19] Barret JP, Gomez P, Solano I, Gonzalez-Dorrego M, Crisol FJ. Epidemiology and mortality of adult burns in Catalonia. Burns : journal of the International Society for Burn Injuries. 1999;25:325-9. [20] Germann G, Barthold U, Lefering R, Raff T, Hartmann B. The impact of risk factors and preexisting conditions on the mortality of burn patients and the precision of predictive admission-scoring systems. Burns : journal of the International Society for Burn Injuries. 1997;23:195-203.

[21] Kerby JD, McGwin G, Jr., George RL, Cross JA, Chaudry IH, Rue LW, 3rd. Sex differences in mortality after burn injury: results of analysis of the National Burn Repository of the American Burn Association. Journal of burn care \& research : official publication of the American Burn Association. 2006;27:452-6

[22] O'Keefe GE, Hunt JL, Purdue GF. An evaluation of risk factors for mortality after burn trauma and the identification of gender-dependent differences in outcomes. J Am Coll Surg. 2001;192:153-60. [23] Benito-Ruiz J, Navarro-Monzonis A, Baena-Montilla P, Mirabet-Ippolito V. An analysis of burn mortality: a report from a Spanish regional burn centre. Burns : journal of the International Society for Burn Injuries. 1991;17:201-4.

[24] Thombs BD, Singh VA, Halonen J, Diallo A, Milner SM. The effects of preexisting medical comorbidities on mortality and length of hospital stay in acute burn injury: evidence from a national sample of 31,338 adult patients. Ann Surg. 2007;245:629-34.

[25] McGwin G, Jr., George RL, Cross JM, Rue LW. Improving the ability to predict mortality among burn patients. Burns : journal of the International Society for Burn Injuries. 2008;34:320-7.

[26] Stylianou N, Buchan I, Dunn KW. A model of British in-hospital mortality among burns patients. Burns : journal of the International Society for Burn Injuries. 2014.

[27] Ludvigsson JF, Andersson E, Ekbom A, Feychting M, Kim JL, Reuterwall C, et al. External review and validation of the Swedish national inpatient register. BMC public health. 2011;11:450. 
[28] Sjoberg F, Danielsson P, Andersson L, Steinwall I, Zdolsek J, Ostrup L, et al. Utility of an intervention scoring system in documenting effects of changes in burn treatment. Burns : journal of the International Society for Burn Injuries. 2000;26:553-9.

[29] Ludvigsson JF, Otterblad-Olausson P, Pettersson BU, Ekbom A. The Swedish personal identity number: possibilities and pitfalls in healthcare and medical research. Eur J Epidemiol. 2009;24:65967.

[30] Charlson ME, Pompei P, Ales KL, MacKenzie CR. A new method of classifying prognostic comorbidity in longitudinal studies: development and validation. Journal of chronic diseases. 1987;40:373-83.

[31] Sundararajan V, Henderson T, Perry C, Muggivan A, Quan H, Ghali WA. New ICD-10 version of the Charlson comorbidity index predicted in-hospital mortality. Journal of clinical epidemiology. 2004;57:1288-94.

[32] Tarrier N, Gregg L, Edwards J, Dunn K. The influence of pre-existing psychiatric illness on recovery in burn injury patients: the impact of psychosis and depression. Burns : journal of the International Society for Burn Injuries. 2005;31:45-9.

[33] Holmes WJ, Hold P, James MI. The increasing trend in alcohol-related burns: it's impact on a tertiary burn centre. Burns : journal of the International Society for Burn Injuries. 2010;36:938-43. [34] Davis CS, Esposito TJ, Palladino-Davis AG, Rychlik K, Schermer CR, Gamelli RL, et al. Implications of alcohol intoxication at the time of burn and smoke inhalation injury: an epidemiologic and clinical analysis. Journal of burn care \& research : official publication of the American Burn Association. 2013;34:120-6.

[35] Kraft R, Herndon DN, Al-Mousawi AM, Williams FN, Finnerty CC, Jeschke MG. Burn size and survival probability in paediatric patients in modern burn care: a prospective observational cohort study. Lancet. 2012;379:1013-21.

[36] Masud D, Norton S, Smailes S, Shelley O, Philp B, Dziewulski P. The use of a frailty scoring system for burns in the elderly. Burns : journal of the International Society for Burn Injuries. 2013;39:30-6. 
[37] Rockwood K, Song X, MacKnight C, Bergman H, Hogan DB, McDowell I, et al. A global clinical measure of fitness and frailty in elderly people. CMAJ : Canadian Medical Association journal = journal de l'Association medicale canadienne. 2005;173:489-95. 
TABLE 1. Personal and clinical details of patients who survived and those who died.

\begin{tabular}{lllll}
\hline & Total & Patients who survived & Patients who died & p value \\
\hline Total, $\mathrm{n}$ & 772 & $725(94)$ & $47(6)$ & $19(40)$ \\
Female sex, $\mathrm{n}^{*}$ & $233(30)$ & $214(30)$ & $72(46-89)$ & 0.16 \\
Age, years** & $34(1-72)$ & $31(1-67)$ & $40.5(12-89)$ & $<0.0001$ \\
TBSA \%** & $7.5(1-34)$ & $6(0.75-29.5)$ & $30.5(2-85.5)$ & $<0.0001$ \\
Full thickness burns \%** & $0.25(0-18)$ & $0(0-13)$ & $38(81)$ & $<0.0001$ \\
Required mechanical ventilation, ${ }^{*}$ & $161(21)$ & $123(17)$ & $28(60)$ & $<0.0001$ \\
One or more coexisting condition, $\mathrm{n}^{*}$ & $133(17)$ & $105(14)$ & $<0.0001$ \\
\hline
\end{tabular}

Data are number (\%) or median $\left(10^{\text {th }}-90^{\text {th }}\right.$ centile). TBSA \%= total body surface area. ${ }^{*}$ Fisher's exact test. **Mann-Whitney U tests 
TABLE 2. Personal and clinical details of patients with and without coexisting morbidity.

\begin{tabular}{|c|c|c|c|c|}
\hline & Total & $\begin{array}{l}\text { Patients with } \\
\text { coexisting morbidity }\end{array}$ & $\begin{array}{l}\text { Patients without } \\
\text { coexisting morbidity }\end{array}$ & $\mathrm{p}$ value \\
\hline Total, $\mathrm{n}$ & 772 & 133(17) & 639(83) & \\
\hline Age, years** & $34(1-72)$ & $64(15-85)$ & $28(1-62)$ & $<0.0001$ \\
\hline TBSA $\% * *$ & $7.5(1-34)$ & $9.4(1-43)$ & $7(1-33)$ & 0.09 \\
\hline Required mechanical ventilation, $\mathrm{n}^{*}$ & $161(21)$ & $44(33)$ & $117(18)$ & 0.0001 \\
\hline Patients who died* & $47(6)$ & $28(21)$ & $19(3)$ & $<0.0001$ \\
\hline
\end{tabular}

Data are number (\%) or median $\left(10^{\text {th }}-90^{\text {th }}\right.$ centile). TBSA \%= total body surface area. *Fisher's exact test. ${ }^{* *}$ Mann-Whitney U tests. 
TABLE 3. Frequency of different coexisting conditions in relationship to the survival status

\begin{tabular}{|c|c|c|c|c|}
\hline Comorbidities & Total & Patients who survived & Patients who died & p value* \\
\hline All & 772 & 725 & 47 & \\
\hline Myocardial infarction & $22(3)$ & $16(2)$ & $6(13)$ & 0.002 \\
\hline Congestive heart failure & $14(2)$ & $9(1)$ & $5(11)$ & 0.002 \\
\hline Peripheral vascular disease & $7(1)$ & $7(1)$ & $0(0)$ & 1 \\
\hline Cerebrovascular disease & $32(4)$ & 23(3) & $9(19)$ & $<0.001$ \\
\hline Dementia & $4(1)$ & $1(0)$ & $3(6)$ & 0.002 \\
\hline Chronic pulmonary disease & $25(3)$ & 23(3) & 2(4) & 0.92 \\
\hline Connective tissue disease & $8(1)$ & $7(1)$ & $1(2)$ & 0.80 \\
\hline Ulcer disease & $8(1)$ & $5(1)$ & $3(6)$ & 0.02 \\
\hline Mild liver disease & $11(1)$ & $9(1)$ & $2(4)$ & 0.28 \\
\hline Diabetes & $27(3)$ & 21(3) & $6(13)$ & 0.008 \\
\hline Diabetes with end organ damage & $6(1)$ & $4(1)$ & $2(4)$ & 0.092 \\
\hline Hemiplegia or paraplegia & $6(1)$ & $6(1)$ & $0(0)$ & 1 \\
\hline Moderate to severe renal disease & $10(1)$ & $5(1)$ & $5(11)$ & $<0.001$ \\
\hline Cancer & $19(2)$ & $12(2)$ & $7(15)$ & $<0.001$ \\
\hline Moderate to severe liver disease & $3(0)$ & $2(0)$ & $1(2)$ & 0.34 \\
\hline Metastatic solid tumour & $1(0)$ & $0(0)$ & $1(2)$ & 0.12 \\
\hline HIV / AIDS & 0 & 0 & 0 & $\mathrm{NN}$ \\
\hline \multicolumn{5}{|l|}{ Psychiatric disorders, } \\
\hline None & $669(87)$ & $634(87)$ & $35(74)$ & \\
\hline Mild & $37(5)$ & $35(5)$ & $2(4)$ & $1^{* *}$ \\
\hline Severe & $32(4)$ & $24(3)$ & $8(17)$ & $<0.001^{* *}$ \\
\hline Mild+Severe & $34(4)$ & $32(4)$ & $2(4)$ & $1^{* *}$ \\
\hline Alcohol abuse & $69(9)$ & $60(8)$ & $9(19)$ & 0.036 \\
\hline Drug abuse & 23(3) & 19(3) & $4(9)$ & 0.09 \\
\hline
\end{tabular}

Data are number (\%).* p value compares frequencies of each pre-existing conditions between survivors and deaths, with the Fisher's exact test. ${ }^{* *}$ The p values are calculated with those who did not have any psychiatric disorder as reference. 
TABLE 4. Logistic regression for mortality analysing the effect of Charlson Index, psychiatric disorders or substance misuse.

\begin{tabular}{lccccc}
\hline & Coefficient & SE & p value & OR & 95\%CI \\
\hline Charlson Index & 2.16 & 0.33 & $<0.001$ & 8.71 & $4.54-16.7$ \\
Psychiatric disorders & & & & \\
$\quad$ None & & & & & \\
Mild & -0.54 & 0.78 & 0.49 & 0.58 & $0.12-2.71$ \\
$\quad$ Severe & 1.58 & 0.52 & 0.003 & 4.86 & $1.74-13.6$ \\
$\quad$ Mild+ Severe & -0.62 & 0.81 & 0.44 & 0.54 & $0.11-2.60$ \\
Alcohol misuse & 0.23 & 0.49 & 0.64 & 1.26 & $0.48-3.27$ \\
Drug misuse & 0.05 & 0.70 & 0.95 & 1.05 & $0.26-4.11$ \\
Constant & -3.59 & 0.25 & $<0.001$ & & \\
\hline
\end{tabular}

Model pseudo $\mathrm{R}^{2}=0.16$, log likelihood = -148.2, $\mathrm{n}=772$. 
TABLE 5. Personal and clinical details of patients who survived and those who died, using categorised variables according to the Galeiras model.

\begin{tabular}{|c|c|c|c|}
\hline & Total & Patients who survived & Patients who died \\
\hline Total & 772 & 725 & 47 \\
\hline Female sex & 233 & 214 & 19 \\
\hline Required mechanical ventilation* & 161 & 123 & 38 \\
\hline \multicolumn{4}{|l|}{ Age in years } \\
\hline$<40$ & 435 & 434 & 1 \\
\hline $40-59$ & 183 & 171 & 12 \\
\hline $60-79$ & 107 & 89 & 18 \\
\hline$\geq 80$ & 47 & 31 & 16 \\
\hline \multicolumn{4}{|l|}{ TBSA burned \% } \\
\hline$<20$ & 603 & 596 & 7 \\
\hline 20-39 & 109 & 94 & 15 \\
\hline $40-59$ & 38 & 25 & 13 \\
\hline $60-79$ & 10 & 6 & 4 \\
\hline$\geq 80$ & 12 & 4 & 8 \\
\hline \multicolumn{4}{|l|}{ Full thickness burns \% } \\
\hline$<10$ & 647 & 636 & 11 \\
\hline $10-19$ & 54 & 48 & 6 \\
\hline $20-59$ & 60 & 39 & 21 \\
\hline$\geq 60$ & 11 & 2 & 9 \\
\hline
\end{tabular}

Data are number.* Individuals who required mechanical ventilation within $72 \mathrm{~h}$ after admission. TBSA\%= total body surface area. 
TABLE 6. Logistic regression with the mortality by Galeiras model combined with Charlson Index and psychiatric disorders, all patients.

\begin{tabular}{|c|c|c|c|c|c|}
\hline & Coefficient & SE & $\mathrm{p}$ value & OR & $95 \% \mathrm{CI}$ \\
\hline Female sex & 0.37 & 0.61 & 0.54 & 1.45 & $0.44-4.76$ \\
\hline Required mechanical ventilation & 3.29 & 0.81 & $<0.001$ & 26.8 & $5.46-131$ \\
\hline \multicolumn{6}{|l|}{ Age } \\
\hline 0-39 years & -4.07 & 1.47 & 0.006 & 0.02 & $0.001-0.31$ \\
\hline 40-59 years & & & & 1.00 & \\
\hline 60-79 years & 2.92 & 0.88 & 0.001 & 18.6 & 3.30-105 \\
\hline 80 years and older & 4.98 & 1.14 & $<0.001$ & 145 & $15.4-1365$ \\
\hline \multicolumn{6}{|l|}{ TBSA $\%$} \\
\hline $0-19 \%$ & & & & 1.00 & \\
\hline $20-39 \%$ & 0.57 & 0.81 & 0.48 & 1.76 & $0.36-8.53$ \\
\hline $40-59 \%$ & 4.49 & 1.11 & $<0.001$ & 89.4 & $10.2-784$ \\
\hline $60-79 \%$ & 2.23 & 1.48 & 0.13 & 9.28 & $0.50-170$ \\
\hline $80 \%$ and more & 3.02 & 2.08 & 0.15 & 20.6 & $0.35-1214$ \\
\hline \multicolumn{6}{|l|}{ Full thickness burns \% } \\
\hline $0-9 \%$ & & & & 1 & \\
\hline $10-19 \%$ & -0.44 & 0.78 & 0.57 & 0.64 & $0.14-2.98$ \\
\hline $20-59 \%$ & 0.50 & 0.77 & 0.52 & 1.65 & $0.36-7.49$ \\
\hline $60 \%$ and more & 4.67 & 2.23 & 0.04 & 106 & $1.34-8394$ \\
\hline Charlson Index & 1.11 & 0.59 & 0.06 & 3.04 & $0.95-9.74$ \\
\hline \multicolumn{6}{|l|}{ Psychiatric disorders } \\
\hline None & & & & 1 & \\
\hline Mild & -2.29 & 1.19 & 0.06 & 0.10 & $0.01-1.04$ \\
\hline Severe & 1.82 & 0.90 & 0.04 & 6.19 & $1.06-35.9$ \\
\hline Mild+Severe & 0.98 & 1.26 & 0.43 & 2.66 & $0.22-31.3$ \\
\hline Constant & -8.01 & 1.22 & $<0.001$ & & \\
\hline
\end{tabular}




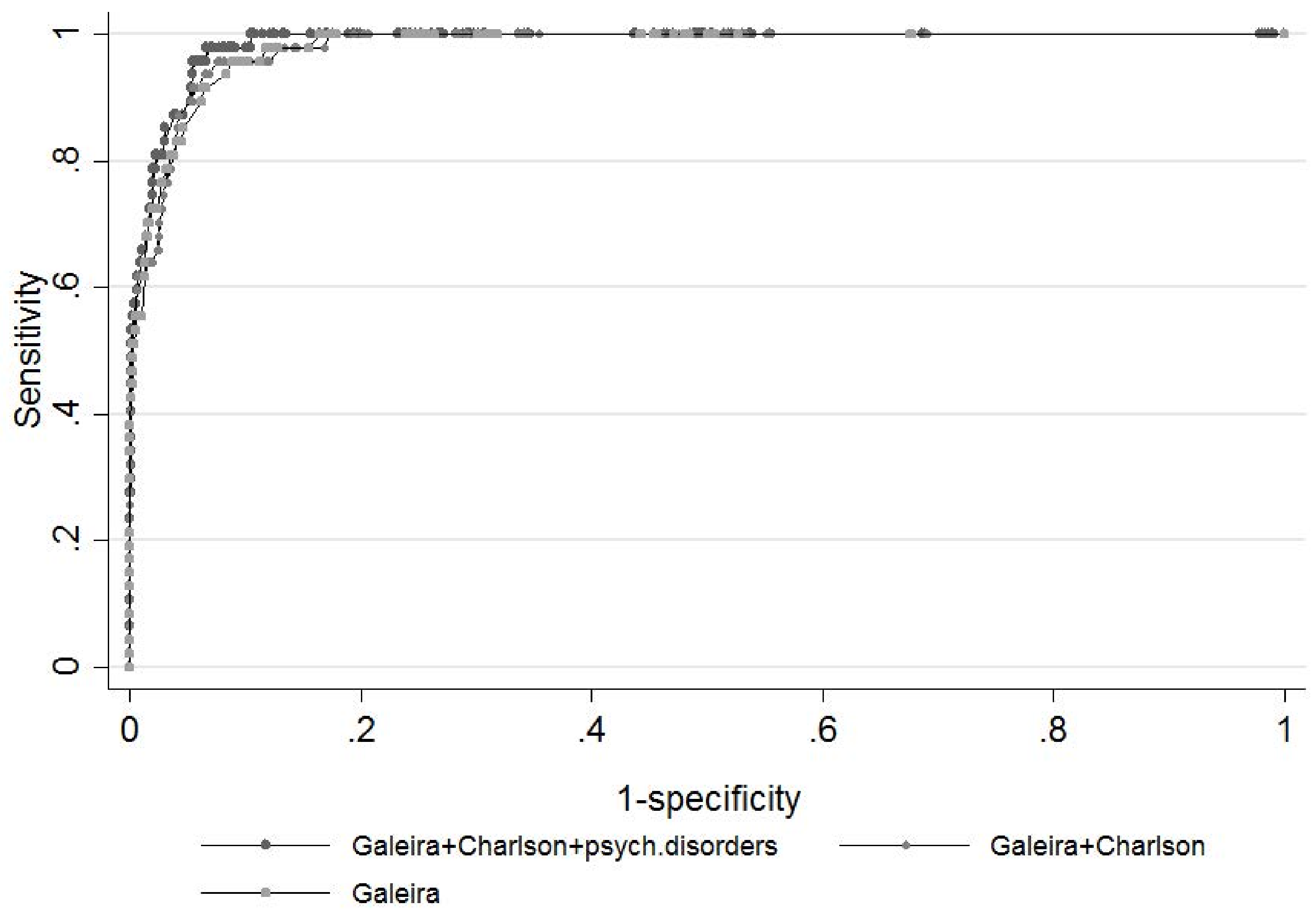


Fig. 1. Area under curve (AUC) for following mortality prediction models: Galeiras with variables age, TBSA\%, FTB\%, gender and MV; Galeiras + Charlson: combination of Galeiras model and Charlson Index; Galeiras + Charlson + psych. disorders: combination of Galeiras model with Charlson Index and psychiatric disorders (mild and severe). 
TABLE A.1 Diagnostic categories, Charlson Weighted Index, ICD-9-SE and ICD-10-SE Codes

\begin{tabular}{|c|c|c|c|}
\hline Conditions & $\begin{array}{l}\text { Charlson Weighted } \\
\text { Index }\end{array}$ & ICD-9-SE & ICD-10-SE \\
\hline Myocardial infarct & 1 & $410,412,411 \mathrm{C}$ & I21,I22,I23,I241,I252,U98 \\
\hline Congestive heart failure & 1 & 428 & I50,I110,I130 \\
\hline Peripheral vascular disease & 1 & 441,443A-443X,785E,V434 & I70-I74,I77 \\
\hline Cerebrovascular disease & 1 & $430-438$ & I6,G45-46 \\
\hline Dementia & 1 & $290,291 C$ & F00-F03,F051,F10.7A,G30 \\
\hline Chronic pulmonary disorders & 1 & $49,500-505$ & J4,J60-J67,J68.4,J70.1,J70.3,J84.1,J92.0,J96.1,J98.2,J98.3 \\
\hline Connective tissue disease & 1 & 710,714A-710C,517,725 & M05,M06,M08,M09,M30-M36,D86 \\
\hline Peptic ulcer & 1 & $531-534$ & K22.1,K25-K28 \\
\hline Mild liver disease & 1 & 571 & B18,K700,K701-K703,K709,K71,K73,K74,K760 \\
\hline Diabetes & 1 & 250A,250C,250G,251C & E100,E101,E106A,E109,E110,E111,E119 \\
\hline Diabetes with complications & 2 & $250 \mathrm{D}-250 \mathrm{~F}$ & E10.2-E10.8,E11.2-E11.8 \\
\hline Hemiplegia & 2 & $342,344 \mathrm{~B}$ & G81,G82 \\
\hline Renal disease & 2 & $\begin{array}{l}\text { 582,583A,583B,583C,583E,5 } \\
\text { 83G,583H,583W,583X,585,58 } \\
6,588\end{array}$ & I12,I13,N00-N05,N07,N11,N14,N17-N19,Q61 \\
\hline Cancer & 2 & $\begin{array}{l}14,15,16,170,171,172,174,175 \\
, 176,179,18,190,191,192,193 \\
194,195,20\end{array}$ & C00-C75,C81-C85,C88,C90,C91-C95,C96 \\
\hline
\end{tabular}


Metastatic cancer

Severe liver disease

HIV/ AIDS
196-199

572

079J,279K
C76-C80

B15.0,B16.0,B16.2,B19.0,K70.4,K72,K76.6, K76.7,I85

B20-B24,Z219 
TABLE A.2 Psychiatric diagnostic categories, ICD-9-SE and ICD-10-SE codes

\begin{tabular}{lll}
\hline Conditions & ICD-9-SE & ICD-10-SE \\
\hline Severe psychiatric diagnoses & 293A-B, 293W, 294A, 295, 295A- & F049, F050, F058, F060-066, F068, \\
H, 295W, 295X, 296A-H, 296W, & F200-206, F208-209, F219, F220, \\
297, 297B-D, 297W, 297X, 298, & F228, F229, F230-233, F238, F239, \\
298A-E, 298W, 298X, 299A, 299X, & F249, F250-252, F258, F259, F289, \\
300A-B, 300D-F, 301A-E, 307B, & F299-302, F308-323, F328-334, \\
307F, 308D, 310A, 311, 318A-C, & F338- 340, F410-413, F418-422, \\
333E & F428-430, F500-503, F600, F601, \\
& F605, F681, F710, F711, F718-721, \\
& F728-731, F738-840, F842
\end{tabular}

Mild psychiatric diagnoses,
293X, 296X, 299B, 299W, 300B, 300C, 300E, 300G, 300H, 300W, 300X, 301F-H, 301W, 301X, 302CE, 302G, 302H, 302W, 302X, 306F, 307A, 307C-H, 307W, 307X, 309A, 309C-E, 309W, 309X, 310B, 310C, 310W, 310X, 312D, 312W, 312X, 313A-D, 313W, 313X, 314A, 314J, 314W, 314X, 315A-E, 315W, 315X, 316, 317, 319, 332B, 333A-D, 333F$\mathrm{H}, 333 \mathrm{~W}, 333 \mathrm{X}, 347,607 \mathrm{~W}, 608 \mathrm{~W}$, 625A, 625W, 780A, 780F, 780X, 787G, 799X, 995C, V15W, V61B, V61C, V61W, V61X, V62C-E, V62W, V65C, V71A
F059, F067, F070-F072, F078, F079, F099, F300, F341, F348, F349, F38, F380, F381, F388, F399, F400, F401-409, F431, F432, F438-454, F458, F459,F480, F481, F488, F489, F504, F505, F508, F509, F510-515, F518-F531, F538, F539, F549, F599, F602-609, F619621, F628-633, F638, F639, F640, F648, F649, F652-654, F658, F659, F660-662, F668, F669, F680, F682, F699-701, F708, F709, F780, F781, F788-791, F798-803, F808-813, F818, F819, F829, F839, F841, F843-845, F848, F849, F889, F899901, F908-913, F918-920, F928933, F938-942, F948-952, F958, 
F959, F980-986, F988, F989, F999,

G210, G211, G240, G251, G259,

G470, G471, G474, G479, N484,

N508, N941, N948, R159, R418,

R699, T749, T887, Z032, Z558,

Z567, Z600, Z603, Z634, Z637-

639, Z728, Z765, Z911

Alcohol misuse

Drugs misuse
303A, 305A, 303X, 291, 291A291F, 291W, 291X

292, 292A-C, 292W, 292X, 304, 304A-H, 304W, 304X, 305C-H, 305X
F100-F109

F110- F169, F180-F199, F559 
TABLE A.3. Presence of coexisting medical conditions in different age group.

\begin{tabular}{|c|c|c|c|c|c|c|c|c|c|c|c|c|}
\hline \multirow[b]{2}{*}{ Pre-existing medical conditions } & \multirow[b]{2}{*}{ Total } & \multirow[b]{2}{*}{ Survivors } & \multicolumn{10}{|c|}{ Age groups, years } \\
\hline & & & $0-9$ & $10-19$ & $20-29$ & 30-39 & $40-49$ & $50-59$ & $60-69$ & $70-79$ & 80-89 & $>90$ \\
\hline All & 772 & 725 & 175 & 93 & 82 & 85 & 89 & 94 & 62 & 45 & 34 & 13 \\
\hline Myocardial infarct & 22 & 16 & 0 & 0 & 0 & 0 & 1 & 0 & 8 & 4 & 6 & 3 \\
\hline Congestive heart failure & 14 & 9 & 0 & 0 & 0 & 0 & 0 & 1 & 2 & 5 & 5 & 1 \\
\hline Peripheral vascular disease & 7 & 7 & 1 & 0 & 0 & 0 & 0 & 0 & 1 & 4 & 1 & 0 \\
\hline Cerebrovascular disease & 32 & 23 & 0 & 0 & 0 & 1 & 1 & 5 & 8 & 9 & 6 & 2 \\
\hline Dementia & 4 & 1 & 0 & 0 & 0 & 0 & 1 & 0 & 0 & 2 & 1 & 0 \\
\hline Chronic pulmonary disease & 25 & 23 & 9 & 3 & 0 & 0 & 5 & 1 & 1 & 3 & 3 & 0 \\
\hline Connective tissue disease & 8 & 7 & 1 & 0 & 0 & 0 & 1 & 2 & 2 & 1 & 1 & 0 \\
\hline Ulcer disease & 8 & 5 & 0 & 0 & 0 & 0 & 1 & 1 & 5 & 0 & 1 & 0 \\
\hline Mild liver disease & 11 & 9 & 0 & 0 & 1 & 2 & 4 & 1 & 2 & 1 & 0 & 0 \\
\hline Diabetes & 27 & 21 & 0 & 2 & 1 & 0 & 3 & 3 & 6 & 5 & 5 & 2 \\
\hline Diabetes with end organ damage & 6 & 4 & 0 & 0 & 0 & 0 & 0 & 0 & 3 & 1 & 2 & 0 \\
\hline Hemiplegia & 6 & 6 & 0 & 0 & 1 & 1 & 1 & 1 & 2 & 0 & 0 & 0 \\
\hline Renal disease & 10 & 5 & 1 & 1 & 0 & 0 & 0 & 0 & 1 & 5 & 1 & 1 \\
\hline Cancer & 19 & 12 & 0 & 0 & 0 & 0 & 0 & 2 & 5 & 2 & 7 & 3 \\
\hline Moderate or severe liver disease & 3 & 2 & 0 & 0 & 0 & 0 & 0 & 2 & 0 & 1 & 0 & 0 \\
\hline Metastatic solid tumor & 1 & 0 & 0 & 0 & 0 & 0 & 0 & 0 & 0 & 0 & 1 & 0 \\
\hline HIV/ AIDS & 0 & 0 & 0 & 0 & 0 & 0 & 0 & 0 & 0 & 0 & 0 & 0 \\
\hline Severe psychiatric disorders & 66 & 56 & 0 & 2 & 10 & 6 & 17 & 17 & 11 & 2 & 0 & 1 \\
\hline Mild psychiatric disorders & 71 & 67 & 4 & 8 & 11 & 6 & 17 & 9 & 9 & 4 & 3 & 0 \\
\hline Alcohol misuse & 69 & 60 & 0 & 4 & 4 & 7 & 22 & 19 & 8 & 5 & 0 & 0 \\
\hline Drugs misuse & 23 & 19 & 0 & 0 & 5 & 3 & 9 & 2 & 3 & 1 & 0 & 0 \\
\hline
\end{tabular}

Data are number, $n$. 